FRUHMITTELALTERLICHE STUDIEN

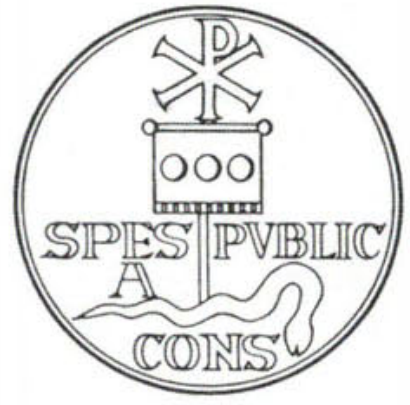





\title{
FRUHHMITTELALTERLICHE STUDIEN
}

\author{
Jahrbuch des Instituts für Frühmittelalterforschung \\ der Universität Münster
}

\author{
in Zusammenarbeit mit \\ Hans Belting, Hugo Borger, Dietrich Hofmann, Karl Josef Narr \\ Friedrich Ohly, Karl Schmid, Ruth Schmidt-Wiegand, Rudolf Schützeichel \\ und Joachim Wollasch \\ herausgegeben von \\ KARL HAUCK
}

14. Band

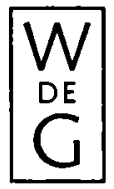

1980

WALTER DE GRUYTER - BERLIN · NEW YORK 
Dieses Jahrbuch ist im Sonderforschungsbereich 7: 'Mittelalterforschung' entstanden und wurde auf seine Veranlassung unter Verwendung der ihm von der Deutschen Forschungsgemeinschaft zur Verfügung gestellten Mittel gedruckt.

(c)

ISBN 3110082454

Copyright 1981 by Walter de Gruyter \& Co., vormals G. J. Göschen'sche Verlagshandlung - J. Guttentag, Verlagsbuchhandlung - Georg Reimer - Karl J. Trübner - Veit \& Comp. - Printed in Germany Alle Rechte des Nachdrucks, einschließlich des Rechtes der Herstellung von Photokopien und Mikrofilmen, vorbehalten.

Satz und Druck: Arthur Collignon GmbH, Berlin 30

Bindearbeiten: Lüderitz \& Bauer, Berlin 